\title{
Simplified mitral valve repair in pediatric patients with connective tissue disorders
}

\author{
Luca A. Vricella, MD, FACS, ${ }^{a}$ William A. Ravekes, MD, ${ }^{a}$ Eloisa Arbustini, MD, ${ }^{b}$
}

Robert D. B. Jaquiss, MD, ${ }^{\mathrm{c}}$ Constantine Mavroudis, MD, ${ }^{\mathrm{a}}$ Harry C. Dietz, MD, ${ }^{\mathrm{a}}$ Marshall L. Jacobs, MD, ${ }^{\mathrm{a}}$

Narutoshi Hibino, $\mathrm{MD}, \mathrm{PhD},{ }^{\mathrm{a}}$ and Duke E. Cameron, $\mathrm{MD}^{\mathrm{a}}$

\begin{abstract}
Background: In pediatric patients with connective tissue disorders (CTDs), early cardiac presentation often involves severe mitral regurgitation (MR) associated with severe bileaflet prolapse and, less frequently, aortic root enlargement. We adopted a simplified repair to address MR and prevent systolic anterior motion (SAM) in this unique group of patients.
\end{abstract}

Materials and Methods: Retrospective review of clinical and echocardiographic data of all pediatric patients (age $<18$ years) with CTD and MR undergoing simplified repair at 3 institutions (2000-2014).

Results: Eighteen children who underwent surgery for severe MR and bileaflet prolapse were identified. All were treated with ring annuloplasty and Alfieri edge-to-edge repair. Median age and weight were 8.2 years (range, $0.4-17.2$ years) and $24.9 \mathrm{~kg}(5.6-63.3 \mathrm{~kg})$, respectively. Median left ventricular end diastolic dimension median $z$ score was 4.9 (2.1-11.9). One patient died (5.6\%), and there were no other major complications. Among survivors, $94.4 \%$ had mild regurgitation or less, with no stenosis or SAM at median clinical follow-up of 2.4 years (range, 0-13.9 years). Median left ventricular end-diastolic dimension $z$ score regressed to 1.3 ( -0.5 to 4.3 ).

Conclusions: In pediatric patients with CTD and severe MR, a simplified approach is associated with intermediate-term competence, absence of SAM or significant stenosis, and regression of left ventricular enlargement. (J Thorac Cardiovasc Surg 2017;153:399-403)

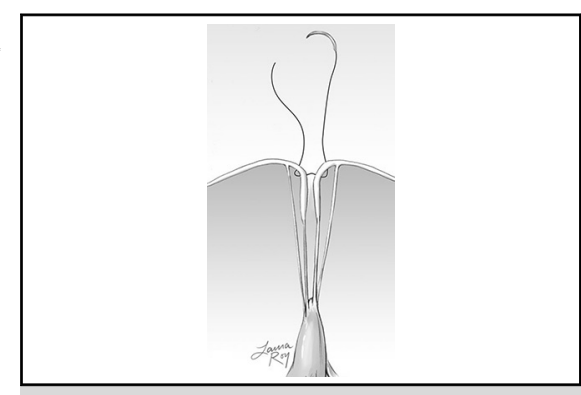

Simplified technique for mitral valve repair (edge-toedge repair).

\section{Central Message}

In pediatric patients with $\mathrm{CTD}$ and severe MR, a simplified approach is associated with intermediate-term competence, no SAM or significant stenosis, and regression of left ventricular enlargement.

\section{Perspective}

In pediatric patients with connective tissue disorders and severe MR, repair involving the valve leaflet or cordal apparatus is often difficult. Ventricular function following acute increase in afterload after repair might be poorly tolerated. We present a multicenter experience with a simplified, reproducible technique aimed at correcting regurgitation while avoiding systolic anterior motion and mitral stenosis.

See Editorial Commentary page 404

\footnotetext{
From the a Division of Cardiac Surgery, Johns Hopkins University School of Medicine, Baltimore, Md; ${ }^{b}$ Center for Inherited Cardiovascular Diseases, IRCCS Foundation, University Hospital Policlinico San Matteo, Pavia, Italy; and ${ }^{\mathrm{c}}$ Division of Cardiac Surgery, Duke University, Durham, NC.

Read at the Annual Mitral Conclave of The American Association for Thoracic Surgery, New York, NY, April 23-24, 2015.

Received for publication Feb 23, 2016; revisions received Aug 30, 2016; accepted for publication Sept 2, 2016.

Address for reprints: Luca A. Vricella, MD, FACS, Division of Cardiac Surgery,

Johns Hopkins University, 1800 Orleans St, Zayed 7107G, Baltimore, MD

21287 (E-mail: lvricella@jhmi.edu).

$0022-5223 / \$ 36.00$

Copyright (c) 2016 by The American Association for Thoracic Surgery

http://dx.doi.org/10.1016/j.jtcvs.2016.09.039
}

Pediatric patients with connective tissue disorders (CTDs) will present in early childhood with aortic root enlargement, mitral regurgitation (MR), or both. MR is often the mode

Scanning this QR code will take you to a video for the article. 


\section{Abbreviations and Acronyms \\ CTD = connective tissue disorder \\ $\mathrm{LV} \quad=$ left ventricle \\ LVEDD = left ventricle end-diastolic dimension \\ MFS = Marfan syndrome \\ MR = mitral regurgitation \\ SAM = systolic anterior motion \\ VSRR = valve-sparing aortic root replacement}

of early clinical presentation in patients with severe infantile Marfan syndrome (MFS), ${ }^{1,2}$ whereas patients with Loeys-Dietz syndrome and other forms of CTDs will more frequently present, initially, with aortic root enlargement. ${ }^{3,4}$ From a morphologic standpoint, patients with CTD will usually manifest severe bileaflet mitral valve prolapse, annular enlargement, and left ventricular (LV) dilation. Mitral valve repair, rather than mechanical replacement, is clearly the preferred approach, whenever feasible for a growing patient, to minimize complications of chronic anticoagulation. ${ }^{5,6}$

During the past decade, we have used a simplified approach in pediatric and adult patients with CTD, severe bileaflet prolapse, and MR. We reviewed the cumulative experience of 3 centers to assess the short- and intermediate-term durability of this technique.

\section{MATERIALS AND METHODS}

A retrospective analysis of all patients with diagnosis of CTD who had undergone mitral valve repair was undertaken at 3 institutions (Johns Hopkins University, University of Pavia, and Duke University). Medical records and echocardiographic data of all patients age $<18$ years who had undergone mitral valve repair consisting of ring mitral annuloplasty and an Alfieri edge-to-edge valvuloplasty (Figure 1) were reviewed. Values are expressed as median (and range) unless otherwise specified. All operations were performed with conventional cardiopulmonary bypass and mild or moderate hypothermia. Mitral valve procedures were performed with aortic crossclamping and cardioplegic arrest. In combined procedures, the mitral valve repair was generally performed before procedures directed at the aortic root or tricuspid valve. This retrospective review was approved by the institutional review boards of the respective institutions.
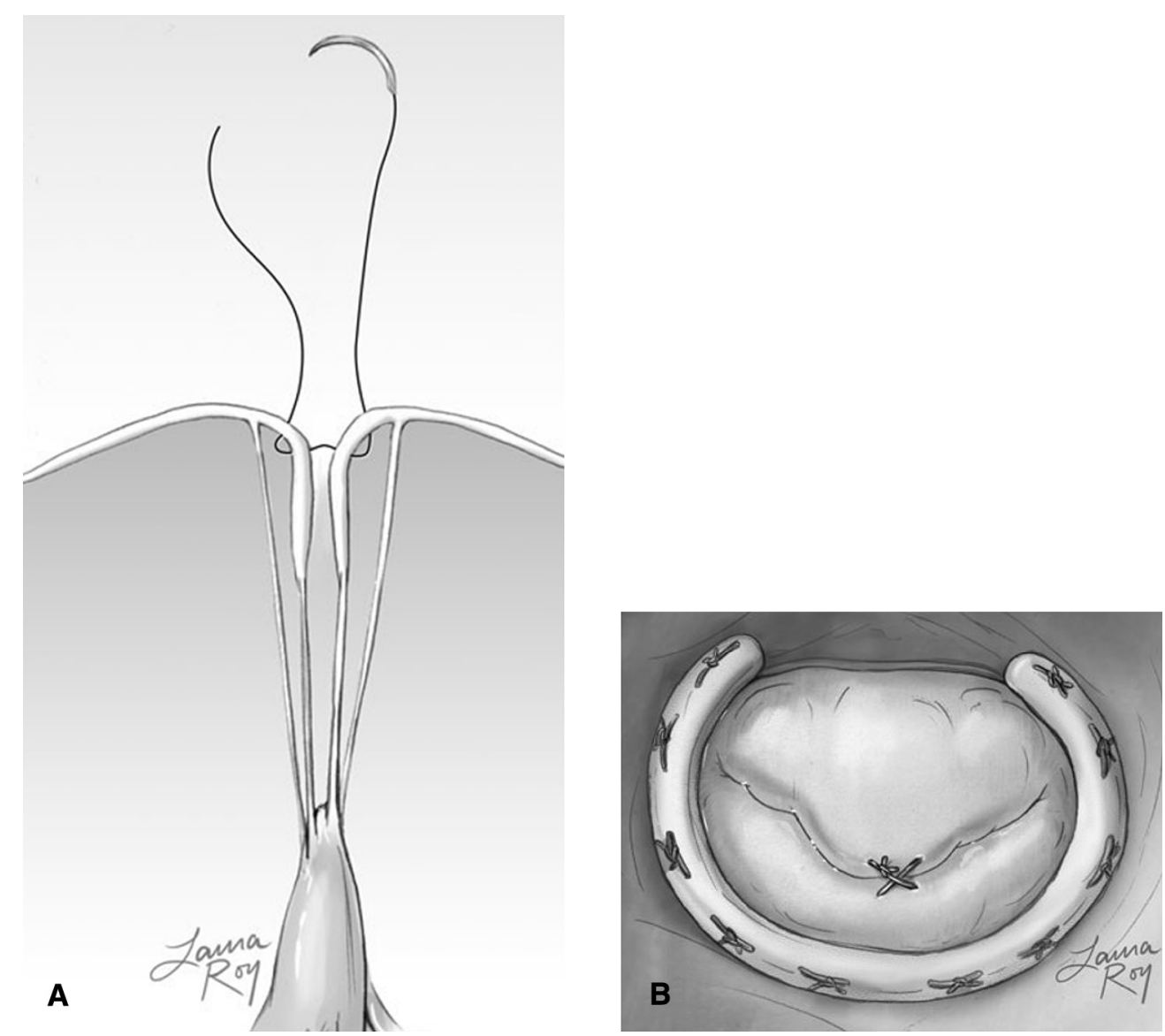

FIGURE 1. Simplified technique for mitral valve repair (edge-to-edge repair and ring annuloplasty). A, Sagittal, schematic view: The anterior and posterior leaflets are brought together by a figure-of-eight or short running full-thickness braided suture brought through and through across the zone of apposition between the 2 mitral valve leaflets, away from their free margin. B, En face view of the mitral valve. A ring annuloplasty has been completed and followed by Alfieri edge-to-edge suture valvuloplasty. 
TABLE 1. Preoperative patient characteristics

\begin{tabular}{lccc}
\hline \multicolumn{1}{c}{ Characteristic } & n & \multicolumn{1}{c}{$\%$} & \\
\hline Women & 11 & 61.1 & \\
Marfan syndrome & 15 & 83.3 & \\
\hline & Mean & Median & Range \\
\hline Age (y) & 8.1 & 8.2 & $0.4-17.2$ \\
Weight (kg) & 27.6 & 24.9 & $5.6-63.3$ \\
Ejection fraction (\%) & 58 & 61 & $35-74$ \\
Left ventricular end-diastolic & 5.1 & 4.9 & $2.1-11.9$ \\
$\quad$ dimension $z$ score & & & \\
\hline
\end{tabular}

\section{RESULTS}

Between 2000 and 2014, 18 pediatric patients undergoing simplified mitral valve repair were identified. Preoperative patient characteristics are summarized in Table 1. All children had severe preoperative bileaflet prolapse with 4+ MR and mostly preserved left ventricular function (median left ventricular ejection fraction, 58\%; range, $35 \%-74 \%$ ). Left ventricular dilation was present in all patients, with preoperative $\mathrm{LV}$ end-diastolic dimension (LVEDD) $z$ score ranging between 2.1 and 11.9 (median, 4.9). A 4-month-old, 5.6-kg infant with severe infantile MFS, intractable heart failure, and severe emphysema was ventilator-dependent and being considered for mechanical support as a possible bridge to cardiac transplantation. The remainder of the procedures were undertaken on an elective basis.

Mean crossclamp time for isolated mitral valve repair was $57 \pm 18$ minutes, and an adult-size ring annuloplasty ring $(26-32 \mathrm{~mm}$ ) was placed in all cases (Video 1). Five patients $(27.8 \%)$ required simultaneous valve-sparing aortic

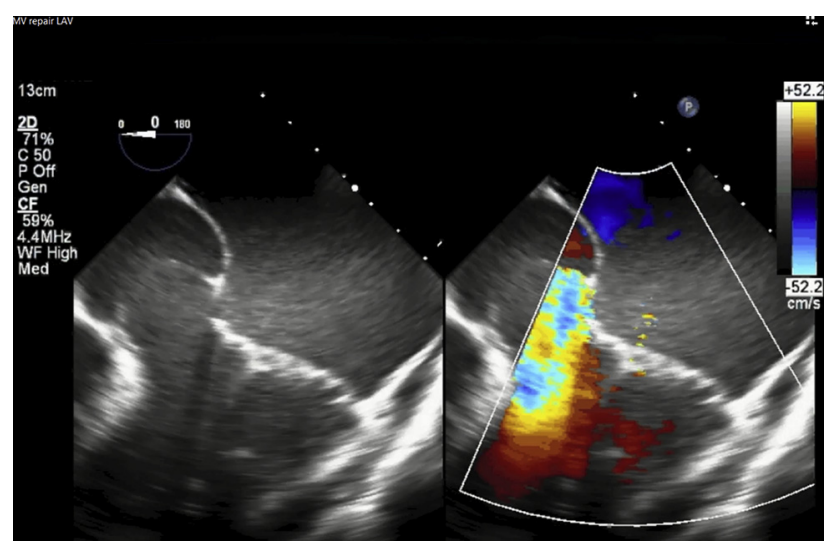

VIDEO 1. The video illustrates a simplified mitral valve repair technique in a young patient with Marfan syndrome, severe pectus deformity, and $4+$ mitral valve regurgitation subsequent to extensive bileaflet prolapse. Video available at: http://www.jtcvsonline.org/article/S0022-5223(16) 31157-6/addons. root replacement (VSRR), whereas 2 (the 3-month-old infant in the cohort and a 2-year-old child) required concomitant ring tricuspid annuloplasty.

One patient died $(5.6 \%)$; the child had undergone simultaneous VSRR and successful mitral valve repair (mild MR on immediate postoperative transesophageal echocardiography) and experienced acute, catastrophic mediastinal bleeding immediately following extubation. The 17 survivors had no major perioperative complications, with a median postoperative stay of 9 days (range, 4-83 days). The infant with severe emphysema required a tracheostomy.

At latest median echocardiographic follow-up of 1.7 years (range, $0-12.4$ years), MR was trivial, mild, and moderate in $8(44.4 \%), 9(50.0 \%)$, and $1(5.6 \%)$ patients, respectively. None of the patients was found to have significant stenosis and none had evidence of systolic anterior motion (SAM). We observed an encouraging reduction in median LVEDD $z$ score from 4.9 to 1.3 (range, -0.5 to 4.3) following repair (Figure 2). Only 1 patient (the infant in the cohort) required reoperation during the follow-up interval, undergoing successful VSRR with reimplantation technique at age 11 months.

\section{DISCUSSION}

Pediatric patients with CTDs will often present with important mitral valve pathology. The typical morphology observed is that of bileaflet prolapse and regurgitation, resulting from the combination of leaflet redundancy and annular enlargement. Patients with severe infantile MFS will frequently present in infancy with mitral valve regurgitation before the development of significant aortic root enlargement, the latter more typically being observed later in childhood. When indications to proceed with surgical intervention for severe mitral valve regurgitation are present, ${ }^{7}$ several factors must be considered: the pathophysiology of the disease; the possible need for reintervention during childhood or later in life on either the mitral valve or aortic root; and the desirability, for obvious reasons, of avoiding the need for anticoagulation during childhood

Furthermore, pediatric patients with CTD will often present substantial additional challenges to surgical repair such as skeletal abnormalities (pectus excavatum and/or severe scoliosis), limited pulmonary reserve, and concomitant need for aortic root intervention or tricuspid annuloplasy. In addition, patients with CTD can disclose limited tolerance to acute correction of MR and the resulting immediate postoperative increase in LV afterload, ${ }^{8,9}$ potentially requiring substantial perioperative support with inotropic and afterload-reducing agents. These important issues must be kept in mind at the time of mitral valve intervention, with the goal of expeditiously achieving an effective and durable repair. 


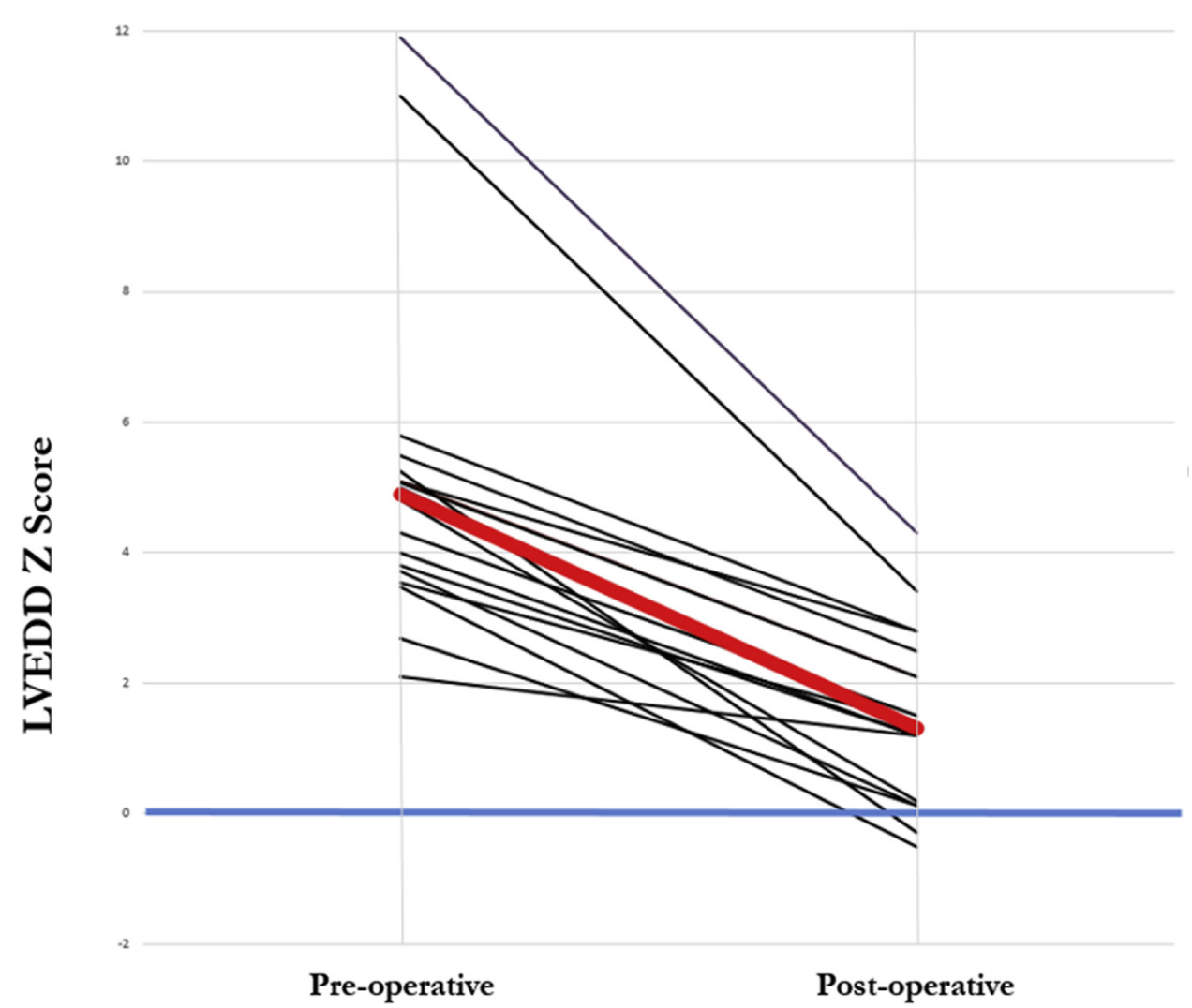

FIGURE 2. Comparison between preoperative and postoperative left ventricular end-diastolic dimension (LVEDD) $z$ scores. Black lines indicate individual LVEDD $z$ scores. Red lines indicate median LVEDD $z$ score for the entire cohort.

Several techniques have been used to correct mitral valve regurgitation in the setting of bileaflet prolapse in children. ${ }^{10}$ These include leaflet resection, cord or papillary muscle shortening, chordal transfer, and insertion of artificial chords, in addition to stabilization of the mitral annulus with a ring annuloplasty. Although effective, these techniques imply a substantial learning curve and are not routinely used by surgeons who deal primarily with congenital heart disease. Either failure of these techniques in less experienced hands, or the assumption that these more complicated procedures are necessary to achieve satisfactory and durable mitral valve repair, may in turn lead to a lower threshold for valve replacement. ${ }^{11}$

The technique of edge-to-edge mitral valve repair was originally described in adult patients by Alfieri and colleagues, ${ }^{12-15}$ and is illustrated in Figure 1. The technique is simple, easily reproducible, and its efficacy in correcting complex prolapse can be rapidly assessed. The ring annuloplasty should be performed first; we use a partial annuloplasty band (Cosgrove-Edwards annuloplasty band; Edwards LifeSciences, Irvine, Calif), at least 2 sizes larger than the measured intertrigonal distance. This is done to avoid undersizing, and to minimize the chance of postoperative mitral stenosis. As in this series, most pediatric patients with CTD will accept a ring of adult dimensions, obviating the concerns for somatic outgrowth of the repair. Apposition of the A2 and P2 scallops of the mitral valve is then performed with a 2-0 or 3-0 braided suture (Ethibond Excel; Ethicon, Somerville, NJ) as a figure-8 or short running stitch, tied over a pledget if the leaflet tissue does not appear robust. It is important (Figure 1, A) to place the full-thickness suture away from the free margin of the leaflets. This results in downward displacement of the zone of apposition between anterior and posterior leaflets, preventing persistent prolapse while avoiding SAM.

Most patients in this series had substantial preoperative LV enlargement with preserved ejection fraction, albeit in the presence of severe MR. We were pleased to observe an effective and stable reduction of LVEDD $z$ scores to within normal range (ie, 4.9-1.3) at intermediate-term follow-up.

\section{CONCLUSIONS}

We believe that the technique described offers the ability to effectively correct mitral valve regurgitation in children with CTDs and complex mitral valve prolapse, without causing SAM or stenosis. In addition, it enables a surgeon to effectively and quickly address mitral valve regurgitation 
in this unique group of pediatric patients who might have limited respiratory reserve or need concomitant artic root replacement, without the need for complex intervention on the subvalvular apparatus.

\section{Conflict of Interest Statement}

Authors have nothing to disclose with regard to commercial support.

\section{References}

1. Morse RP, Rockenmaker S, Pyeritz RE, Sanders SP, Bieber RE, Lin A, et al. Diagnosis and management of infantile Marfan Syndrome. Pediatrics. 1990; 86:888-95.

2. Mueller GC, Sark V, Steiner K, Von Kodolitsch Y, Rybczynski M, Weil J, et al. Impact of age and gender on cardiac pathology in children and adolescents with Marfan syndrome. Pediatr Cardiol. 2013;34:991-8.

3. Loeys BL, Schwarze U, Holm T, Callewaert BL, Thomas GH, Pannu H, et al. Aneurysm syndromes caused by mutations in the TGF-beta receptor. $N$ Engl $J$ Med. 2006;355:788-98.

4. Williams JA, Loeys BL, Nwakanma LU, Dietz HC, Spevak PJ, Patel ND, et al. Early surgical experience with Loeys-Dietz: a new syndrome of aggressive thoracic aortic aneurysm disease. Ann Thorac Surg. 2007;83(2 Suppl):S757-63.

5. Kojori F, Chen R, Caldarone CA, Merklinger SL, Azakie A, Williams WG, et al. Outcomes of mitral valve replacement in children: a competing-risk analysis. $J$ Thorac Cardiovasc Surg. 2004;128:703-9.

6. Alsoufi B, Manlhiot C, McCrindle BW, Al-Halees Z, Sallehuddin A, Al-Oufi S, et al. Results of mitral valve replacement with mechanical prostheses in young children. J Thorac Cardiovasc Surg. 2010;139:1189-96.
7. Johnson JT, Eckhauser AW, Pinto NM, Weng HY, Minich LL, Tani LY. Indications for intervention in asymptomatic children with chronic mitral regurgitation. Pediatr Cardiol. 2015;36:417-22.

8. Cook JR, Carta L, Benard L, Chemaly ER, Chiu E, Rao SK, et al. Abnormal muscle mechanosignaling triggers cardiomyopathy in mice with Marfan syndrome. $J$ Clin Invest. 2014:124:1329-39.

9. Hetzer R, Siegel G, Delmo Walter EM. Cardiomyopathy in Marfan syndrome. Eur J Cardiothoracic Surg. 2016;49:561-8.

10. Brizard CP, d'Udekem d'Acoz Y. Chapter 81: Valvular disease in children. In: Yuh DD, Vricella LA, Baumgartner WA, eds. The Johns Hopkins manual of cardiothoracic surgery. 2nd ed. New York: McGraw-Hill; 2014:1243-54.

11. Kim ER, Woong-Han K, Choi ES, Cho S, Jang WS, Kim YJ. Surgical management of mitral regurgitation in patients with Marfan syndrome during infancy and early childhood. Korean J Thorac Cardiovasc Surg. 2015;48:7-12.

12. Alfieri O, Maisano F, De Bonis M, Stefano PL, Torraca L, Oppizzi M, et al. The double-orifice technique in mitral valve repair: a simple solution for a complex problem. J Thorac Cardiovasc Surg. 2001;122:674-81.

13. Pozzoli A, Vicentini L, de Bonis M, Di Giannuario G, La Canna G, Alfieri O Contemporary application of the edge-to-edge repair. Ann Cardiothorac Surg. 2015;4:376-9.

14. De Bonis M, Lapenna E, Lorusso R, Buzzatti N, Gelosmino S, Taramasso M, et al. Very long-term results (up to 17 years) with the double orifice mitral valve repair combined with ring annuloplasty for degenerative mitral regurgitation. $J$ Thorac Cardiovasc Surg. 2012;144:1019-24.

15. De Bonis M, Lapenna E, Taramasso M, La Canna G, Buzzatti N, Pappalardo F et al. Very long-term durability of the edge-to-edge repair for isolated anterio mitral valve prolapse: up to 21 years of clinical and echocardiographic results. J Thorac Cardiovasc Surg. 2014;148:2027-32.

Key Words: mitral valve repair, connective tissue disorders 